\title{
Reflection on my Schooling: From Engineering to Training
}

\author{
Anoj Bhattarai \\ M.sc. Construction Management; B.E. Civil; BBA \\ Program Director, Curriculum Development Program, Training and Education Department, \\ Training Institute for Technical Instruction (TITI) \\ Sanothimi, Bhaktapur, Nepal \\ Email for correspondence: ab@titi.org.np or anoj_bhattarai@yahoo.com
}

\begin{abstract}
This paper reflects the journey of my life and highlights the importance of setting goals for desired achievements in life. Additionally, it scrutinizes the role of patronage of parents, societal influence and cultural capital to set the degree of success a person achieves in his or her life.

Through reflection, the paper advocates for inevitability of technical and vocational contents and multi-disciplinary competencies including international languages and life skills from the early age of schooling to tackle with the challenges of $21^{\text {st }}$ century.
\end{abstract}

Key words: Reflection, Cultural capital, Technical Education and Training.

\section{Background}

Only a few people know me because I am a common person. My family, relatives and friends claim that I am introvert, unsocial and less successful in comparison to my contemporary. I do not find anything extra-ordinary, challenging and filmy to share with other. Still, I believe everyone can relate to my personal life and learn, because I am a common person. The aim of this piece of work is to reflect the journey of my life; the ups and downs, the experiences, the success, the failure, the mistakes I committed, and the learning I gained from those mistakes.

\section{My schooling}

I was brought up in a middle class family. Being a government employee, my father had to work in different geographical locations of the country. As my father was the sole bread provider, we were all dependent on him. Just as the cat shifts its kittens from one place to another, our parents also had to shift me along with my three sisters wherever my father was transferred. Wherever we were shifted, we were enrolled in the government school of that area. There were some places where we were not able to even complete a school year. As a positive consequence of this shifting from place to place, I got exposure to different places, cultures and people. At the same time, I believe, this shifting from place to place has hampered the quality of my formal schooling and education. Bradley (2009) on the basis of the research conducted by Jennifer Warlick, professor of economics and policy studies at the University of Notre Dame, highlights that the students 
who change schools frequently can suffer psychologically, socially and academically. A report produced in 1994 by Health, Education and Human Services Division of General Accounting Office (GAO/HEHS) of United States claims that the frequent school changers have to face many challenges including limited English proficiencythat make learning and achievement difficult for them. (General Accounting Office, 1994). Might be as a frequent school changer, I could never achieve the first position even when there were only two persons in any sector till date. On the other hand, our society is constructed in such a way that the degree of success and failure of a person is measured by ranking a person's grade achievement in his or her education or the money earned rather than viewing from the moral perspective.

For me, the entire examination system practiced in Nepalese education system has a flaw and is questionable. Wagley (2013) claims that in more than 90 per cent of the cases, Nepalese education system adopts norm-referenced subjective examinations where the students are asked to write what they memorize from the textbook by restricting them to apply their creativity. Based on this faulty system, students are tagged as first boy/girl, second boy/girl and so on. Norm-referenced assessment system classifies students and produces a dependable rank order of students. On the contrary, criterionreferenced assessment system determines how well students are doing relative to a pre-determined performance level on a specified set of educational goals or outcomes (Bond, 1996). Nepalese education system should get rid of this conventional normreferenced subjective examination system.

In this way days passed on. A research conducted from April 2006 to March 2007 in Japan found that highly educated/high-income/ regular employee parent expect child to achieve high social status with better academic performance, whereas non-highly educated/non-high income/non-regular employee parents except child to acquire certain vocational skills (Shimonura, Honma, Mimura, Kazuo, \&
Nagasu, 2007). As my parents were also educated, they started giving extra effort towards my study after I reached the 9 th grade. They prepared a study schedule for me. I had to study six extra hours under their guidance despite their busy schedule. Though I was not much aware of the positive consequences, I also started giving more effort. Honestly speaking, I was not intrinsically motivated at that time but the extrinsic motivation provided by my parents worked. As a result, I scored first division in School Leaving Certificate (SLC) examination. Actually, I was the second person in my family circle to score first division in the SLC examination. My parents were proud of me and my image among my relatives got improved. For the first time, I realized that I could also do something if I put in some more extra effort. The overall notion of meritocracy and the feeling that even if I were born in a middle class family I had the potential to rise higher if I were to work harder grew on me. This was the first gentle turning point of my life. Reflecting back, the feeling must have come because education attainment and performance is perceived as a key factor in determining merit (Meroe, n.d.).

I wanted to join an engineering college for my further study because some of my friends were also planning to do the same. But, my parents advised me to join intermediate in science (I.Sc) so that I would have a variety of choices for my further study. I thought I was grown-up and I should have freedom to take decision on my own. I simply rejected my parents' advice and joined engineering college to study diploma in civil engineering. At this stage, a person is highly influenced by friends. Peer group has a stronger relationship with the personality development of a person when compared to parent (Bestur, 2007). I now realize that it was one of the wrong decisions for rejecting my parent's advice. In my understanding, the patronage of the parents is must, because children with involved parents tend to earn academic excellence, have better social skills, are more likely to be socially competent, have better communication skills and likely go on to further education (Parentalrigths.org, 2014). 
However, unfortunately, that time, I was very happy, because I got what I wanted to do. My life was full of freedom. Due to this, my focus shifted from study to other unproductive activities. I used to say; "even if I could not pass any subjects I would still be certified as a sub-overseer after three years. Why should I worry?" I had no aim in my life. "Why should I try to learn?" This type of mentality was embedded in my mind. Now I have realized that one should have to set goals for desired achievements in life. Setting goals insures dedication and focus, promotes accountability and inspires to be the best that one can be. There is a positive correlation between goals and performance (Lunenburg, 2011). In addition, I believe that, at least up to certain age a person needs proper guidance, control, care and counseling. Ignoring the advice of the parents was a blunder. Though my parents were very caring, I misused the freedom provided by them. It is unfair to blame my parents, but now, I have realized that the parents should not give unnecessary freedom to their offspring.

By chance, I completed diploma in civil engineering within the allocated time frame. Since, I had no aim for further study; I started hunting for a job. I was attracted by immediate benefits. Despite the fact that my family was able to support my further education, I started working and ignored my family's offer/advice by repeating the same mistake. For a couple of months, I was very happy with my job and earning but my parents were not. My relatives started blaming my parents for not giving me proper guidance and support. All the relatives and family circle started regarding me as an idiot, useless, unproductive and even a bad son though I did not have any kind of bad habits-that normally our community labels as bad habits. They have set academic degree as an indicator of individual excellence rather than viewing it as a combination of innate abilities, hardworking, having the right attitude and having high moral character and integrity (McNamee \& Miller, 2004). I do agree I was introvert, little bit unsocial but not an idiot, useless or unproductive. There was no way; I could have been a bad son. That allegation really pinched me. I then slowly started rationalizing the context. I also started to compare myself with other colleagues, friends and relatives of my age who were continuing their education. Some of them were only studying while some were continuing simultaneously with their work. I asked myself, "If they can do, why cannot I do?"

There is a phrase, “विख नभएको सर्प र ईख नभएको मान्छे, काम लागदैन", upon translation, a snake without poison and a person without vision or jealousy is useless. This phrase really forced me to set the vision for my life. In addition, I should be thankful to the relatives, the family circle, the circumstances and my cultural capital that forced me to accept the challenge. As Bourdieu says, the social class effects on children's educational success and is mediated by both parental and children's cultural legacy. Children inherit parental cultural capital and children's cultural capital is converted into educational credentials (Sullivan, 2002). Now, I was keen and intrinsically motivated to continue my education. This was the second turning point of my life.

Though I decided to continue my education, it was not as easy as I thought. I had to cross many hurdles.

For instance, my degree of proficiency in intermediate level was not up to the par, on the basis of which I could compete and get admission easily in bachelor's degree in civil engineering. My father wanted to send me the then USSR for further study, but my mother denied to send me there. She had a fear of losing her son. She thought if I went there, I would never come back. She feared that I could marry a Russian girl and be settled there. As a result, I additionally wasted extra five productive years.

There is a saying, "where there is a will, there is a way". After five years, I got admission to continue my further study in civil engineering in my own country. But fortunately, during the five years period, when I was struggling to get an admission in engineering, I completed bachelor's degree in business administration along with my work; that 
later on added some value to my professional career. Job taught me to work with different people in different informal settings and formal schooling taught me to acquire required knowledge. In fact, I had already started jumping from one discipline to another. In today's multidisciplinary job environment, being able to understand different perspectives and work with people in other fields has served me well. Meza (2009) claims that one should learn two skills so that if one of them does not work out, he/she always has the second one to fall back on for a job.

I second on his understanding because industry/market demands a mix of skills and talents. They are looking for people who can work across the traditional boundaries of a linear discipline and competent enough in multidisciplinary skills. In today's age, a multi-disciplinary portfolio is valued over a linear one. In my understanding, our education practices must be developed in such a way that one can evolve his/her competencies to adapt and succeed in a multi-disciplinary fashion.

When somebody is intrinsically motivated and committed for something good, nothing can stop her or him to achieve her or his goals. Here, I completed my bachelor's degree in civil engineering with good rank and within the allocated time frame, because this time I was intrinsically motivated. I decided to continue my education and job simultaneously. As a result, I completed Master of Science in Construction Management. Because of the maturity and experience, I have now realized the needs of lifelong learning and I am committed for it. In my opinion, to cope with the challenges of 21 st century, one should understand the importance of lifelong learning and take necessary initiatives to continue learning throughout the life.

\section{My career}

At the early stage of my career, I was working as a civil overseer. My employers were satisfied with my performance. During that time, I did not find any kind of difficulty to perform the job. Most of the time, I had to visit different places for surveying and supervision. I mean to say, I was doing the same for which I was trained in the college. The life was easy going, but later on, I realized that it was immature feeling and wrong decision of my life.

When I completed bachelor's degree in civil engineering, I started working as an engineer for private engineering companies. Though the hierarchy was higher and the responsibilities were expanded, nature of the job was almost similar to the previous stage. My parents and relatives were happy with my progress because the label of "Engineer" was tagged with my name. Some of the occupations such as doctor, engineers, lawyers and officers/executives of government/public organizations are considered as high status job in our society. The National Opinion Research Center (NORC) has assembled jobs by prestige according to which, civil engineer is one of the top twenty highly prestigious jobs (Davis, Smith, Hodge, Nakao, \& Treas, 1989).

Unlike in the first stage of my professional career, this time that was not enough for me. I wanted to have something more. Frankly speaking, I was not satisfied with my academic progress and the job in private companies. The government jobs are considered on the top level, stable and secured as compared to private sectors (ib.id.). Hence, I wanted to work for government organization where I would have a secured job with good respect and status. In addition, my parents and other family members had started suggesting me to settle down with prestigious and permanent job. Therefore, I started hunting for a government job.

I was continuing master's degree simultaneously with my job. In the meantime, I got an opportunity to work for Training Institute for Technical Instruction (TITI). TITI was established in 1991 as a Nepalese national institute under the umbrella of Council for Technical Education and Vocational Training (CTEVT) as a separate semi-autonomous institution mandated for the training and development of TVET teachers including principals, curriculum developers and community facilitators (Subedi, 2012). CTEVT is a national autonomous apex body of Nepal 
government. Since, I was looking for secured and stable job with full of status, I decided to join that organization which later on proved as a major turning point of my life. Though the nature of the job was entirely different with respect to my academic background and experiences, I overlooked that reality, attracted by the status, job security, and physical infrastructure of the organization; I forced myself to compromise with the situation. This time I was not working as an engineer. I was appointed as a trainer whose major duty was to train the technical and vocational teachers and managers of technical schools in different areas such as instruction, management, curriculum development, facilitation and presentation skills and information technology related skills. Here I realized that the cultural and social context of family and community influence a job choice decisions for a youth (Feny, 2006). My parents used to say "राजाको सिन्दुर लगाए जीवन सफल हुन्छ," Upon translation, a person needs to get government job to succeed. Might be that thought was embedded in my mind also, that might be the reason for scarifying engineering profession and blindly jumping into the new occupation as a trainer for Training Institute for Technical Instruction.

Despite the aforementioned reality, I have been working since the last twelve and half years for the same organization entirely in a new profession with some ups and downs. I consider this tenure as a major and important phase of my career. In fact, in real sense, my professional journey starts from this organization. Steffy (2000) has provided a model for career stages that a person pass through as $\mathrm{s} / \mathrm{he}$ copes with his or her job. The model includes five career stages viz. anticipatory career stage, expert/master career stage, withdrawal career stage, renewal career stage and exit career stage. Steffy claims, a person in the anticipatory career stage tends to be idealistic, has high energy level and believes $\mathrm{s} /$ he can make a difference. A person is close to obtain a goal s/he has set for him/herself. An individual is close to obtaining a goal and volunteers for extra work. In addition, s/he is open to new ideas, creative and talks about the work with others. This exactly fitted in my case as well. During this stage,
I was enthusiastic; I had a high energy level. I used to think that I could make a difference and could do whatever I wanted to do. I used to put extra effort to meet the target and used to share about my job with my parents, relatives and friends. Most of the time, I was extremely motivated to work.

During this stage, I went through a hard time as well. Because of the nature of the job that was different to my academic background; I had to put some extra effort to learn the job. Sometimes, I used to ask myself, what if I were in the same occupation for which I was trained. Despite these dilemmas, another core problem was my English language competency. As the foundation of my education was extremely weak and as I was studying in Nepali medium, I used to find difficulty when I had to communicate and deliver the sessions in English medium. I do agree that this is the age of globalization and neoliberalization. These two key forces have contributed for inevitability of English language (Phyak, 2012). My bitter experience for not having strong English language competency and lacking in various areas inspires me to advocate for implementing English medium from the very early stage of our school system without disrespecting the native languages to avoid huge hindrance in the future of our kids. In my understanding, if a person really wants to compete in global market, it is for sure that he/she should be competent enough to deal in English language.

Only lacking in English language, I got frustrated and wanted to quit the job. I might have gone through the early withdrawal stage if I had not taken corrective measures. Fortunately, despite these difficulties and problems; the working environment, support I got from colleagues and supervisors, and the learning culture of the organization rescued me to cross this stage successfully.

A person at the expert/master career stage is in control of his/her environment, not only competent but also confident and self-actualized through the job. Maslow (1954) says a person at this stage tries to fulfill his/her own potential by seeking more and more responsibility and by working harder and 
harder. When I reflect myself, during this stage I got many opportunities to successfully complete many challenging projects. I also got many opportunities to work as international consultant/trainer for different countries. These are some remarkable instances, which I consider as cornerstones of my success during this stage. On top of that, my job had been enlarged and enriched. Job enrichment through a promotion helped me to renew my career. All these progresses became possible because I did not giveup and put some extra effort to improve my weak areas such as English language competency and presentation skills. So far, I have not gone through the exit career stage, in which stage an individual is about to leave the system (Steffy \& Wolfe, 2001). Transformation of engineering expertise to teaching

I have been equipped with Bachelor's Degree in Civil Engineering from Institute of Engineering, Tribhuvan University and Master's Degree in Science in Construction Management from Pokhara University of Nepal. The curricula of both levels have been developed in such a way that they cover multidisciplinary subjects.

Working as a trainer for TVET teachers, managers and occupational curriculum developers, I have realized that the knowledge, experience, understanding and skills I had acquired in the engineering sector are highly transferable and vibrant. During training implementation, I need to nurture and support my trainees to challenge theories and principles, provide the examples of applications of such theories and principle, and encourage them for logical thinking and problem solving activities. I share my knowledge and experiences in a way that motivates them to learn more, support creativity, and bring innovative ideas in the classroom and workplace.

As an occupational curriculum developer and a trainer, I used to cash my engineering expertise to develop and implement competency-based training (CBT). Collum (1994) states that the philosophy of CBT is captured in the famous quote of William Blank i.e. "Human competence is the ability to perform. Knowledge, attitude and effort are of little value without results." According to him, the minimum criteria for CBT are: content directly related to work, focus on doing and evaluation is based on industry work standards (Collum, 1994). For me, a person who is expert in a particular field can better understand, develop and implement training programs rather than a person from general background who has only pedagogical and facilitation skills. That might be the reason; I am getting relatively more opportunities than my colleagues are to provide consultancy services at international level too. In this regard, in the present context, this profession has become a "hotcake" for me. I mean to say, it is now one of the highly salable professions in Nepal.

\section{Theorizing my life}

When I reflect my schooling, my cultural capital rescued my life and really pushed me up; in fact helped me to study further. My parents and social circle provided me with cultural capital by transmitting the attitudes and knowledge needed to get success in my life.

When I was intrinsically motivated, I achieved longlasting success. However, to some extent, extrinsic motivation also worked when I was young. During my professional career, my personal interest and self-determined extrinsic motivational factors tracked me in a different direction away from my cultural capital.

Vroom's expectancy theory suggests that the motivation that leads to job satisfaction is a function of the perceived relationship between an individual's effort, performance and the desirability of consequences associated with job performance (Robbins \& Coulter, 2000). Throughout my professional career, I got everything easily and so far, I am fully satisfied. Hence, in my understanding, this theory did not work well in my case.

I sacrificed my choice of working as an engineer and jumped into another profession. Hence, needs theory worked here rather than choice theory. I have always been deeply influenced by Gandhi 
Jee's philosophy of education. He has emphasized that the people should be educated through arts and crafts, work and play, voluntary activity and selfchosen activity (Khanna, 2009). He used to say “simple living high thinking'. Everyone needs to learn from this statement. My experience also taught me to realize that simplicity is the best policy. Everyone has potential and one should not stop learning. There are many ways to reach the destination, if one door is closed, grab the next one. At the same time, I come to realize that the parenting of the parents and society and the learning helps one to develop self-determination. Hence, one should always give respect to his/her family and society and should be committed for lifelong learning.

In addition, to cope with the challenges of $21 \mathrm{st}$ century, every child should be equipped with multidisciplinary competencies. Giving due respect to mother tongue; one should equip him/herself with multi-linguistic competencies especially international languages such as English language. Hence, our education practices must be developed in such a way that one can evolve his/her competencies to adapt and succeed in a multi-disciplinary fashion.

\section{Conclusion}

I never tried to document the reflection of my life before this paper. While writing, I have realized the importance of reflection. One should reflect own life from time to time so that a person can take necessary corrective measures to track the life in the right direction.

Societies have set different indicators to measure the degree of success of a person. Some people set the indicators from the financial perspective, some as the status in the society, while some other see how educated $\mathrm{s} / \mathrm{he}$ is. In my understanding, if a person is educated, rest of the indicators can automatically be fulfilled. For me, quality education is only the panacea to tackle with the problems we face in our life. It took almost half of my life to understand the importance of education and still trying to understand more. Then, how can we expect our children to understand it without guidance? That is why, at least up to certain age, children need proper guidance, counseling, and support including control from their parents, teachers and even from society.

Hence, giving due importance to general education; policy makers, educators and politicians should advocate for the incorporation of technical and vocational contents from the early age of schooling or education. If wisely implemented, technical education does not demand for extra investment, rather it can be done in the local context by using locally available resources and by promoting indigenous knowledge practiced in that locality. Technical education really helps to change from one track to another track easily, as that helped me to transform my career from engineering to training profession. In addition, giving due importance to local languages and indigenous knowledge, education system should focus on international languages, life skills and modern technologies so that the future generation will not have to face the problem which I faced in my life. Hence, my philosophy is "one should equip him/her with multi-disciplinary competencies. Accept the challenges and do not hesitate to change the occupation. If done honestly and with full commitment, success is everywhere".

\section{References}

Bestur, G. (2007). Personality develpment of the adolescent: peer group versus parents. South African Journal of Education, 27(2), 177-190.

Bond, L. A. (1996). Norm and Criterion Referenced Testing. Practical Assessment, Research \& Assessment, 5(2). Retrieved January 15, 2015, from http://PAREonline.net.getun.asp?v $=5 \& n=2$

Bradley, C. C. (2009, July 06). Switching schools affects student achievement, study. Retrieved August 10, 2014, from http://phys.org/ news 166114656.html

Collum, J. (1994). Overview of Competency Based Training (CBT). Concept Card. Kathmandu, Nepal: Swisscontact. 
Davis, J. A., Smith, T. W., Hodge, R. W., Nakao, K., \& Treas, J. (1989). List of Occupation by Prestige. General Social Survey-Inter-University Consortium for Political and Social Rearch.

Delors, J. (1996). Learning: The treasure within Report to UNESCO of the International Commission on Education for the Twenty-first Century. UNESCO.

European Commission. (2001). Making a European Area of LifeLong Learning a Reality. Commission Communication, $\operatorname{COM}(2001) 678$ final.

Feny, N. M. (2006). Factors Influencing Career and Choices of Adolescents and Youth Adults in Rural Pennsylvania. Journal of Extension, 44(3).

General Accounting Office. (1994). Elementary School Children-Many Change Schools Frequently, Harming Their Education. Washington, D.C: Health, Education adn Human Services Division.

Khanna, S. (2009). Education Philosophy (1 ed.). New-Delhi: Essential Books.

Lunenburg, F. C. (2011). Goal-Setting Theory of Motivation. INTERNATIONAL JOURNAL OF MANAGEMENT, BUSINESS, AND ADMINISTRATION, 15(1).

McNamee, S. J., \& Miller, R. K. (2004). The Meritocracy Myth. (G. H. Conklin,, Ed.) Sociation Today, 2(1).

Meroe, A. S. (n.d.). Democracy, Meritocracy and the Uses of Education. The Gordon Comission on the Future of Assessment in Education.

Meza, J. (2009, February 2). Why a Multidisciplinary Education Will Help You Succeed. Retrieved October 2, 2014, from SACNAS: http:// sacnas.org/about/stories/sacnas-news/spring 2009/why-multidisciplinary-education-will-help you-succeed
Muller, F. H., \& Lauw, J. (2003, September). Conditions of University Students'Motivation and Study Interest. Retrieved January 24, 2015, from http://www.Leeds.ac.uk/educol/documents /00005572.htm

Parentalrigths.org. (2014). The Vital Child-Parent Relationship. Retrieved Nobember 12, 2014, fromParentalrights.org: http://www.parentalrights. org/ index.asp?SEC $=\%$ 7B 780255DE-D387 4493-BFDB-1C371844036A\%7D

Phyak. (2012, July 9). Teh English Language in Nepal. The Kathmandu Post. Kantipur Publication.

Robbins, S. P., \& Coulter, M. (2000). Management (5th ed.). New Delhi: Prentice Hall of India Private Limited.

Shimonura, H., Honma, K., Mimura, T., Kazuo, E., \& Nagasu, M. (2007). Parent's Views of Children's Futures and Career Education/Career Guidance. Retrieved from http://www.jil.go.jp/ english/reports/documents/jilpt-research/ no.92.pdf

Steffy, E. B., \& Wolfe, P. M. (2001). A life cycle model for career teachers. Kappa Delta Pi REcord, 38(1), 16-19.

Subedi, B. S. (2012, July). Prospects and Challenges of TVET Teacher Education in the Context of Nepal. TVET Development Journal,1(12), 20 30.

Sullivan, A. (2002). Bourdieu and Education: How Useful is Bourdiew's Theory for Researchers? The Netherland's Journal of Social Sciences, $38(2)$.

Wagley, M. P. (2013, April 23). Our Examination System Highly Subjective and Faulty. Retrieved January 25, 2015, from eduinfo.com: http://eduinfonepal.com 